what would be expected if, in its ontogenetic development, $H$. sapiens departed less from its embryonic form than $H$. neanderthalensis. In other words, $H$. sapiens is simpler or more generalised, and this attribute of his evolution accords well with what has been said above with regard to pædomorphosis. At the same time, of course, $H$. sapiens has also evolved along his own progressive lines.

We therefore suggest that the available evidence may be most profitably synthesised by regarding $H$. neanderthalensis as the antecedent in consanguinity of $H$. sapiens, the descent of the latter having been characterised by pædomorphosis, so that it may be said that $H$. sapiens has derived his main characters from young $H$. neanderthalensis, the adult characters of $H$. neanderthalensis having been discarded and lost by this process. It is interesting to us to note that this view is in substantial agreement with the conclusions with regard to the affinities between $H$. neanderthalensis and $H$. sapiens at which Prof. Hrdlička has arrived from other lines of investigation. ${ }^{5}$

L. H. Dudley Buxton.

University Museum, Oxford, G. R. DE BEER. June 15.

1 Garrod, D., Times, June 11, 1932

2 Bolk, L., Lancet, Sept. 10, 1921; Proc. Konin. Akad. v. Wetensch. te Amsterdam, 25, 1922; “ Das Problem der Menschwerdung ", Jena, 1926.

3 Keith, A., NATURE, Supplement, Aug. 18, 1923.

de Beer, G. R., "Embryology and Evolution", Oxford, 1930.

'Hrdli飞ka, A., J. Roy. Anthrop. Inst., 57, 1927.

\section{Mother-of-Pearl Glouds over Scandinavia in January and February 1932}

THE remarkable stratosphere clouds 1 which the late Prof. Mohn called mother-of-pearl clouds, again appeared over Scandinavia several times during the months of January and February of this year. Elaborate preparations had been made to obtain photographs and visual observations of these remarkable clouds. All my aurora stations in southern Norway were ready to take photographs as soon as the clouds appeared, and Capt. Ween, of the Norwegian Geodetic Survey, in collaboration with me, had made preparations to take photographs with modern photo-theodolites. Further, through the photographic stores of Nerlien in Oslo, I had secured assistance in obtaining photographs and moving pictures of the clouds in natural colours. Through broadcasting and by articles in the Press, I asked people to send me observations of the clouds, and this proved to be a most valuable help, since I received about three hundred most interesting reports from different parts of Scandinavia and Finland.

The clouds were first seen in Oslo on Jan. 14, and during the following week from several parts of northern Norway. On Jan. 27 and 29 they were again seen in Oslo, and about fifty successful photographs for determining the height were secured at my aurora stations in southern Norway. Some photographs were also taken by Capt. Ween. During the following two weeks the clouds were observed on several occasions from southern, central, and northern Norway.

On Feb. 19, clouds of exceptional beauty were seen about sunset in southern Norway; about seventy reports, with sketches, and a series of interesting photographs, were received. In Oslo, I observed the clouds for three hours from sunset and from about midnight until the next morning, the clouds being illuminated by the moon. All my aurora stations were in action, and more than a hundred successful photographs, with base lines 27-3-105 $\mathrm{km}$., were taken, first after sunset and then during the night in moonshine.

No. 3269, VoL. 129]
A series of successful photographs was also taken by Capt. Ween, and four very interesting photographs and a moving picture, both in natural colours, were secured by Mr. Simonsen and Mr. Gibbson, of the firm of Nerlien, Oslo.

The preparation of the large amount of material will undoubtedly reveal much that is new concerning these remarkable clouds. Preliminary measurements of some of the photographs show the same altitudes as before, that is, somewhere between twenty and thirty kilometres.

During the night of Feb. 19-20, I made an interesting observation which may give some idea as to the nature of these clouds. A rather homogeneous cloud happened to be near the moon, and I then observed part of a large corona. From the moon and outwards there was a region of bluish-yellow colour, and then came part of a red ring with an inner radius of between fourteen and fifteen degrees from the moon. The outer radius was not observed. If we assume the outer radius of the red ring to be equal to or greater than $18^{\circ}$, we have ${ }^{2}$ for the cloud particles diameters not exceeding $0.0025 \mathrm{~mm}$.; the height of the clouds was at that time $21.25 \mathrm{~km}$., according to preliminary measurements.

Oslo.

CARL STÖRMer.

1 "Clouds High in the Stratosphere." By Prof. S. Chapman, NATCRE,

April 2, p. 497. Kapitel, Wien und Leipzig, 1922.

\section{Freshwater and Land Mollusca from British Somaliland}

SINCE my letter on climatic changes in British Somaliland was written,1 Major Connolly has kindly identified for me some freshwater and land mollusca from that Protectorate, collected in the Dumuk tug near Buramo, a few miles from the Abyssinian frontier.

They were extracted from the bank of the dry channel under about fifteen feet of alluvium, and include Zebrinops revoili (?) Bgt. and two species of Subulina, known from Gallaland, but not before recorded from British Somaliland, namely, S. erlangeri Bttgr. and lacuum Bttgr.

$Z$. revoili is more or less a desert form. Although these three terrestrial species were found at nearly the same horizon as the freshwater forms and may have fallen or been swept by flood waters into the tug, yet their occurrence at least suggests a pause in deposition when the expanse of alluvium through which the present channel is cut became dry land.

The point is worth investigation, as such a break, if confirmed, may simplify the correlation of variations of climates with other areas.

The remaining species are: (1) the widely distributed Melanoides tuberculata Mull., and (2) Planorbis stanleyi Smith, not previously recorded from British Somaliland, although a living Abyssinian form.

In addition to these five species, $Z$. maunoirianus Bgt. was found on the Sorl Haud between Illad and Heman (lat. $48^{\circ}$ N. and long. E. $10^{\circ}$ ). The distribution of this snail, amongst other details, is given by Connolly in a paper published in $1931 .^{2}$

From the ruins of Gorgab, he identifies Cerastus somaliensis Smith, and another species of that genus, unidentifiable by reason of the fragmentary condition of the specimen, also Sub. erlangeri Bttgr. and Limi. colaria donaldsoni Pilsb.

Two small pieces of the shells of freshwater mussels were picked up amongst the ruins of the old town of Eik, forty miles south of Burao and about thirty from the Abyssinian frontier. These are determined to be (i) a species of Mutela, and (ii) most probably a 